\title{
Comparison of problem solving tools in lean organizations
}

\author{
Maria Virginia Iuga $^{1+2, *}$, and Liviu Ion Rosca ${ }^{2}$ \\ ${ }^{1}$ Marquardt Schaltsysteme S.C.S., 2 München st., 550018 Sibiu, Romania \\ ${ }^{2}$ Lucian Blaga University of Sibiu, Faculty of Engineering, 10 Victoriei Bvd., 550024 Sibiu, Romania
}

\begin{abstract}
As global market competition is getting fiercer, and companies are looking at ways to stay on top, more and more organizations are looking at Lean Manufacturing and lean tools to support them in achieving their goals. Especially within the automotive industry, lean practices are very well received. The speed at which the automotive industry is evolving, especially but not only, in countries like Romania, leads to the need to carefully analyze lean manufacturing concepts, examine them against local production conditions, and to develop and standardize them. One of the most important things to take into consideration here is the application of an adequate problem solving technique to avoid waste. The objective of this research paper lies in analyzing and comparing the problem-solving methods recommended by the Toyota Production System, and to propose their appropriate application at shop floor, in relation to the specific problem type.
\end{abstract}

\section{Introduction}

The word „problem” is widely used in daily, organizational and business language. According to the etymology dictionary, the origins of the term ,problem” is the Latin word „problema”, the Greek , $\pi \rho{ }^{\prime} \beta \lambda \eta \mu \alpha$ ” or the Old French ,problème” meaning ,,a difficulty, a barrier" [1]. Generally, the term is defined as a question involving doubt, uncertainty, or difficulty [2]. In business terms, a problem is defined to be the gap perceived between an existing status and the desired one, or a deviation from a standard [3].

All organizations deal with large pools of problems and challenges. Often, problems are swept under the rug due to either lacking capabilities in resolving them, lack of resources or processes, or due to the fact that they are not being credited with a high importance factor. Frequently organizations will face problems when they are either threatening existing processes and the success of the organization, or when they are so called "quick fixes". Currently not many organizations have solid problem solving techniques and processes in place and even less organizations look at problems as being opportunities rather than threats. The problem solving philosophy from lean manufacturing comes from the main idea of reducing waste, specific the waste of resources generated by an ineffective approach to organizational problems.

\footnotetext{
* Corresponding author: virginiaiuga@gmail.com
} 


\section{Problem solving philosophy in Lean Manufacturing}

The starting point of this paper is Toyota's view of a problem. The problem is viewed as being difficult, a matter of dispute and the antonym to the solution. A problem is therefore unique, time limited, contains a certain risk and complexity while having unknown solution. If it is possible to solve the ,problem“ with the available knowledge or rules, then it must be regarded as a task and is no longer a problem. On the other hand, Toyota has a very mature and efficient way of looking at organizational challenges as being opportunities [4]. Within his research Puvanasvaran [5] states that any problem should be appreciated as an opportunity to improve process and develop people.

There are many ways companies, which identified problems as being organizational opportunities, are dealing with these. Some organizations even assign specific problem solving teams to detect and solve organizational challenges. Some of the more famous methods used by organizations are techniques like audits, brainstorming, checklists for risk identification or benchmarking.

The lean manufacturing problem solving philosophy is an accessible and easy to understand notion. Problem solving in lean manufacturing is a main part of entire Toyota Production System (TPS) philosophy.

Toyota divides problems into three categories and utilizes the resources appropriately for all three levels (Fig.1). Larger issues are generally addressed through managementdetected and management-controlled activities. The way this company manages to increase performance is through leverage and focus. Toyota enforces basic problem-solving to all employees. This way every employee can become a problem solver making it possible for the company to effectively leverage its people resources. For more complex problems which require a high degree of problem solving skills, members of management are trained via Management Kaizen events. According to the Toyota philosophy, the needed information to describe a problem are: the current situation description and the historical trends, the target including the difference between the target and current status, and the detailed description or problem [4].

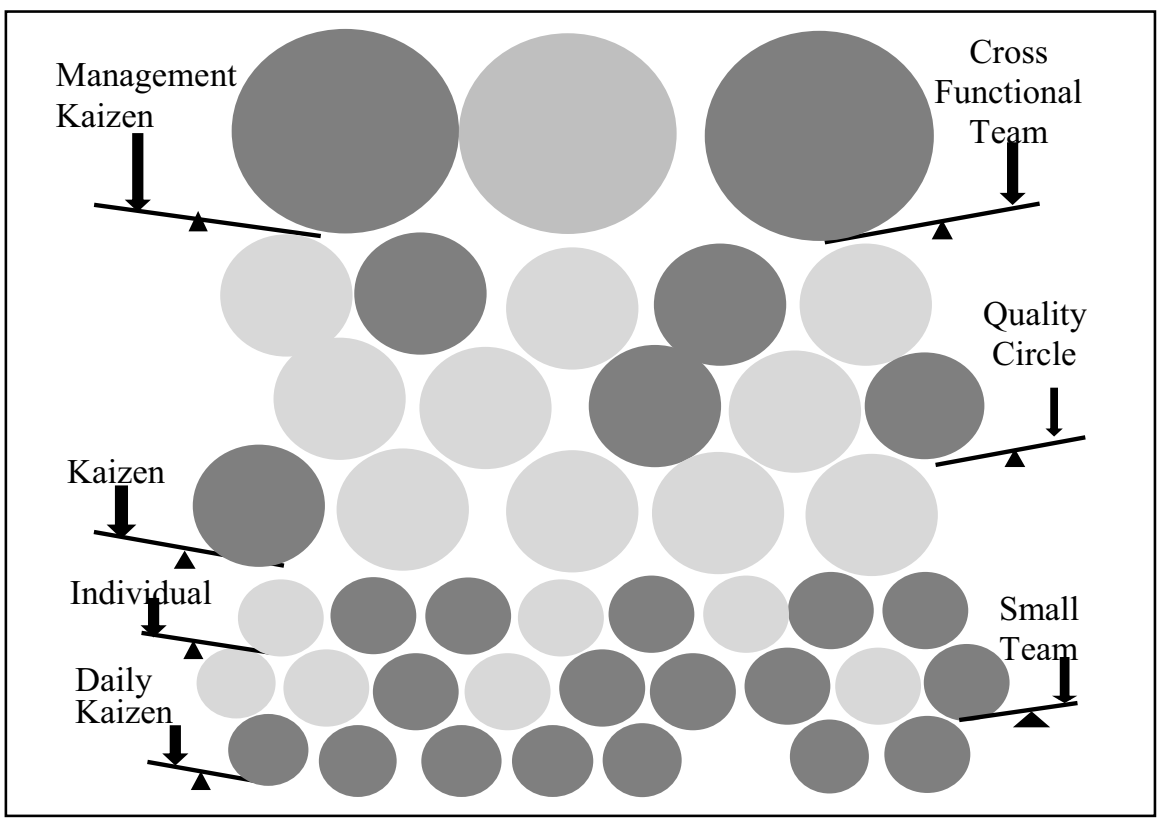

Fig. 1. Toyota problem hierarchy (adapted from [4]) 


\section{Problem solving methods in Lean Manufacturing}

\subsection{Brainstorming}

Increasingly, brainstorming has become an integral part of developing products and processes. Companies utilize brainstorming as a method to reach conclusions about an existing issue or as a means of developing new directions and solutions. It is a method that encourages creative thinking and new ideas. Alex Faickney Osborn coined the term and method back in 1957 in his book, "Applied Imagination". He named the method after the idea, namely "using the brain to storm a problem" [6].

Typically, in the beginning stages of working with teams, producing new ideas begins by attempting to solve existing organizational issues. During the initial idea-generation stage of the decision-making process, brainstorming is used to try and solve issues that can have major or minor consequences on the organization. [7]. A group will function together and consistently generate new ideas and solutions freely without deep assessment or criticism. Ideas are documented visually for members of the group to help develop any possible new concepts.

Various guidelines exist to create a successful brainstorming session amongst organizational members. Originally Alex Faickney Osborn created his own special means to cause an optimal brainstorming session that fosters creativity. Brainstorming directions are as followed: (1) No explanations about contributed ideas; (2) when a lull is happening reengage the group by restating the issue at hand; (3) support or incite non-participating members to add ideas; (4) recommend participants revisit categories when not creating new ideas [8]. The approach developed by Faickney allows each member to fully participate in the brainstorming session. Each member is held accountable for active participation and idea generation to further develop the session. Moreover, by simply focusing on generating ideas, and not dwelling on implications or difficulties involved, members are able move to new ideas and the session can advance with more engagement leading to more solutions. To create many ideas for a given subject, brainstorming is expended as a technique with the focus of deferring assessment until new ideas have been proposed [9].

For many organizations, it is a problem-solving technique that usually requires approximately 20 minutes. Required resources involve flipcharts, pin boards, presentation cards and pens.

Conversely, it is possible for social influences, such as evaluation apprehension, to have an impact on the performance of group members within the organizational brainstorming session and lead to productivity losses. For example, if some group members do not consider themselves to be of the same intellectual or cognitive abilities as others, it may impede their ability to willingly contribute with ideas. A study by Thompson [10], found that if an individual notices that their performance is moderately similar to that of others, they may identify their performance in a more positive way. Furthermore, research has shown that people in groups exert less effort into answering an issue than those who are attempting to solve a problem on their own; this is referred to as free-riding or social loafing [11].

Brainstorming, while still an effective means of collective intelligence, has progressed with technology. Electronic brainstorming is a practice that organizations are using to further expand on group collaboration. Stemming from traditional brainstorming, electronic brainstorming is where members of a group use computers to generate ideas and alternative solutions [12]. Typically, a mediator is present which details the issue at hand as well as the specific targets of the organization. Electronic brainstorming has shown to help participants be more creative without the help of other participants influencing idea generation or 
inspiration. Results have shown that when groups are lacking in creativity and generating new ideas, electronic brainstorming is effective [13].

While the future of brainstorming and idea generation is unknown, it remains a useful tactic for organizations. Discovering new ways to generate solutions is useful to solve existing or potential organizational issues. Managers can use traditional and electronic brainstorming to engage creativity and find resourceful means of sustainability.

\subsection{Ishikawa}

The Ishikawa technique (Cause and Effect Analysis) provides a useful way to explore all the things that could potentially cause a problem. Ishikawa diagrams were popularized by Kaoru Ishikawa in the 1960s and the tool is considered one of the seven basic quality tools. The diagrams are known as Ishikawa Diagrams or Fishbone Diagrams because a completed diagram can look like the skeleton of a fish. Mazda Motors famously used an Ishikawa diagram in the development of the Miata sports car [14].

The Ishikawa diagram shows the relationship between an effect or problem and the potential causes. It allows the categorization of the causes. The seven main factors/ categories of causes are all beginning with "M": Material, Machine, Method, Man, Management, Milieu (Mother Nature, Environment), Measurement. Depending on the problem statement, several „M“s could be omitted or added.

Technically seen, and concerning the required materials, the tool is simple, powerful (particularly in the context of teamwork), easy to learn, and requires little effort.

The cause-effect diagram normally produces good results in a relatively short time while the visual presentation is easy to understand.

\subsection{Why}

The 5Why questioning technique serves to find the real causes ("root causes") of a problem. Determining the root cause of the problem is a technique that implies looking at the problem and asking "Why?" and "What caused this problem". The general rule is to ask five times "why", until the true cause is determined.

Usually the answer to the first "Why" question leads to another "Why" question, therefore, it is called the 5Why technique. The technique was first used by S. Toyoda within the Toyota Company, and is a main component of problem-solving training of the Toyota Production System. Taiichi Ohno (1988) describes this method as being "the basis of Toyota's scientific approach, by repeating "why" five times the nature of the problem as well as its solution becomes clear" [15].

Tracking the causes to the true cause prevents from working on symptoms and helps to find sustainable solutions and to solve a problem on a long term.

The technique is easy to perform and offers a deep root cause analysis. Nevertheless, there is a risk to stop too early with the question of technology, and thus the actual cause is potentially not found or, on the other hand, there are answers that can lead to a dead end, e.g. "The customer wants it that way."

\subsection{Therefore technique}

The "therefore technique" is a technique dedicated to problem identification and has its roots in TPS. While the 5Why technique is used mostly to identify the root cause of a problem to create an approach to solve it, the "therefore technique" helps to find the true problem that occurs in a process. This technique focuses on the problem identification and can be considered as a former step to the application of problem solving tools (PST) such as 
5 Why, Ishikawa, etc. This step assures the discovery of the true problem and then applies the root cause analysis (e.g. 5 why) to the real problem. Also, it will assure that the most effective measures will be applied. Applying the "therefore technique" is mandatory within the Toyota culture in order to make the difference between problems and their symptoms and to correctly detect the root causes and solutions to real problems, and not symptoms.

The general tendency is to find solutions for the symptoms. Analyzing the symptoms can lead to a "dead end", especially when the problems are technical ones. E.g. the 5 Why technique applied to a technical issue can lead to a root cause such as "machine design mistake". The solution to this "cause" can be expensive and complicated. Applying the "therefore technique" leads to an understanding of the real problem. This approach leads to alternative, easy and less expensive solutions, in order to reduce interruptions [4]. The technique will maximize results with minimal efforts and finally will resolve the true problem by correcting causes in addition to the ones initially identified.

The main advantage of the technique is ensuring that the most important opportunities are taken into consideration.

\subsection{Questioning technique (5W\&2H technique)}

The "Questioning" technique concentrated on looking at a problem from all possible angles. It is a method to identify the causes of problems [16]. Its name comes from the letter "w" or "h" that is contained in every of the 7 questions that are: What?, Who?, Where?, When?, Why?, How?, How often / many / much?.

The method can be used in different areas every time when situations have to be analyzed and when it comes to clarifying problems. The main objective consists in a fast and comprehensive analysis of the actual state.

\subsection{Pareto diagram (ABC Analysis)}

The "Pareto Diagram" is a data analysis tool that is used for the selection of a limited number of causes that produce a significant overall effect. In terms of quality improvement, a large majority of problems $(80 \%)$ are produced by a few key causes $(20 \%)$.

A Pareto diagram is a simple bar chart that ranks related measures in decreasing order of occurrence. The principle was developed by Vilfredo Pareto, an Italian economist and sociologist who conducted a study in Europe in the early 1900s on wealth and poverty. He found that wealth was concentrated in the hands of the few and poverty in the hands of the many [17]. The application of the Pareto analysis in risk management allows management to focus on those risks that have the most impact on the project. The method allows to make complex, large amounts of data manageable by sorting and clustering, to visualize a rough picture of the actual work situation, to separate the "essential" from the "inessential" and to set priorities (80:20 rule).

The method requires reasonable effort, is easy to use and allows a very clear graphical representation of results.

\subsection{Seven alternatives ( 7 ways)}

The Seven Alternatives (7 ways) technique is rooted from new product/ process development, formally known as Production Process Preparation (3P). The method is used to encourage creativity with the purpose to generate multiple solutions. Initially used as a part of the $3 \mathrm{P}$ process, the method's objectives are the visualization of relationships between construction and the use of components and assemblies. 
This technique is applicable in all manufacturing processes. The steps to perform the method are as followed:

1. Showing and describing seven alternatives to solve the problem. Usually it is difficult to find seven possible alternative solutions for a problem. Nevertheless, the number of seven must be reached. This forces the participants to seek creative and unusual ideas. For this reason, the collection of ideas is done in the spirit of brainstorming. The focus lies in the invention of new alternatives.

2. Selection of evaluation criteria. These are chosen in relation to the purpose e.g.: Cost, Benefit, Efficiency, Feasibility, Acceptance, Effort for Approval, Duration of Decision Making Processes

3. Evaluation of the alternatives through scoring each solution for all established criteria

4. Selection of the "best" solution - best score

\subsection{Force field analysis}

Analyzing the forces "For" and "Against" change is a common instrument used for systematically studying complex problems. It helps with the visualization of all the factors for and against a plan, with the prioritization of these based on importance of these factors, and with the decision of whether a plan is worthy of being implemented or not. Force Field Analysis was developed by Kurt Lewin [18]. This system was originally meant to be used as a tool in social psychology. Nevertheless, Force Field Analysis is nowadays used in business for taking and communicating go/ no-go decisions. The Force Field Analysis is often used in the initial phase of a problem-solving process.

The method follows the next steps:

- $\quad$ writing the topic, the problem, the target state as a heading on the pin board

- labeling columns ("+"driving forces and "--"restraining forces)

- determining the forces that support the desired goal and the forces that impede the desired state

- $\quad$ identifying the positive and negative forces with priorities, such as "length of an arrow" or visualized with adhesive point

- $\quad$ analyzing and editing the results further. After finding a solution in a problem-solving process, e.g. a counter-check of whether all the positive factors are in place and all the blocking factors are eliminated or weakened.

The method is fast, easy, requires short time (about 10-20 min), takes into consideration all the aspects determined by a team, delivers approaches to positive changes, and visualizes the balance of the effective factors.

Nevertheless, the application of this method alone will lead to solutions and the findings and results from the force field analysis must be further processed.

\subsection{A3 Problem solving story}

The A3 Problem Solving Story is the most specific and complete TPS problem solving technique. This tool was developed by Toyota and represents their approach in problem solving.

The method uses a simple way to collect data and information, followed by a standardized approach for team based problem solving. It is also the easiest way to visually communicate information and ideas - it tells the story and is perfect for facilitating team based problem solving.

The method was part of Toyota's Quality Circle problem solving efforts in the 1960s and it allowed teams to gather the most important information on one sheet of paper (easy to read, understand and base decisions upon). The philosophy starts from the idea of 
concision: if a problem story can't be described in one page, it means the result is not concise enough (the problem solving process is similar to a story, hence the term "Problem Solving Story"). There is an introduction (steps 1-3: problem statement, information, actual situation through facts and figures, objectives) followed by a middle part (step 4: cause and analysis), a main part (steps 5-6: counteractive measures/ alternative solutions; rollout scenario), and finally a conclusion (steps 7-8: documentation/ further actions).

The originality of this method lies in the fact that in order to find a solution it does not need a computer, but only pen, paper, common sense, knowledge, creativity, and sustainability. The method uses the power of other lean hard tools to perform a good analysis. If there is a solution it is important to know, why the solution works. According to Toyota, the method can be used by every employee independent of his/ her experience and education. The method allows stake holders which are closest to the problem to make an impact, while any interested parties can review and draw conclusions. The main disadvantage is that the collected and analyzed data cannot be stored on an IT-system.

The "A3 Problem Solving Story" tool can be applied in a wide range of situations: from half hour problem solving meetings up to several day's problem solving workshops or within large Kaizen projects [4].

\section{METHODS COMPARISON}

Lean Manufacturing problem solving tools can be used depending on problem complexity and their impact by themselves or combined. TPS proposes very different methods: quick and creative ones, analytical, methods that can be applied in small teams or complex methods which require deep analyses and follow-ups of the iterative four-step management method Plan-Do-Check-Act Cycles (PDCA), or methods which help validate solutions, such as A3- Problem Solving.

In a fierce competition market, the decision maker should find rapidly solutions. Time usually do not allow the use of all the above tools. So, what method should be used and when? In order to asses this issue we suggest to compare these methods using six different criteria. These criteria represent, in our opinion and literature, the defining features of these methods (Table 1). Literature provides many scales, scores, utilities, items and so on to be used to differentiate methods or alternatives. For exemplification purposes each method was granted a score between 0 and 3 . In our case, 0 means that the criterion does not describe the method at all, while 3 means that the criterion perfectly describes the method.

So, we suggest:

1. CO - Creativity orientated

2. RC- Root cause analyze orientated

3. CM - Complexity of method

4. IS - Immediate solution oriented

5. AS - Solutions analyze orientated

6. CPX-Appropriate for complex problems

Table 1. Overview of PST

\begin{tabular}{|c|l|c|c|c|c|c|c|}
\hline \multicolumn{2}{|c|}{ Method/Criteria } & CO & RC & CM & IS & AS & CPX \\
\hline A & Brainstorming & 3 & 0 & 1 & 3 & 1 & 1 \\
\hline B & Pareto & 0 & 2 & 1 & 0 & 0 & 2 \\
\hline C & 7 Alternatives & 3 & 3 & 1 & 2 & 3 & 3 \\
\hline D & Force field analyze & 2 & 0 & 1 & 0 & 3 & 2 \\
\hline E & 5 Why & 2 & 2 & 2 & 1 & 0 & 1 \\
\hline
\end{tabular}




\begin{tabular}{|c|l|c|c|c|c|c|c|}
\hline \multicolumn{2}{|c|}{ Method/Criteria } & CO & RC & CM & IS & AS & CPX \\
\hline F & Therefore Technique & 0 & 3 & 2 & 1 & 0 & 2 \\
\hline G & Ishikawa & 1 & 3 & 3 & 0 & 0 & 3 \\
\hline H & 5W\&2H & 0 & 2 & 3 & 0 & 0 & 1 \\
\hline I & Problem Solving Story & 3 & 3 & 3 & 3 & 2 & 3 \\
\hline
\end{tabular}

To obtain a better visualization for choosing the most appropriate method different scatter diagrams can be design as in (Fig. 1-2).

Depending on the problem, needs and possibilities, this kind of visualization will facilitate the decision of which method or methods should be used and when.

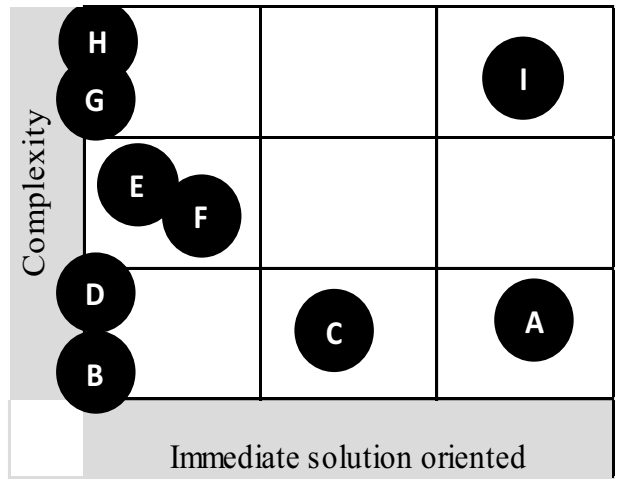

Fig. 1. Scatter diagram: PST complexity vs. immediate solution

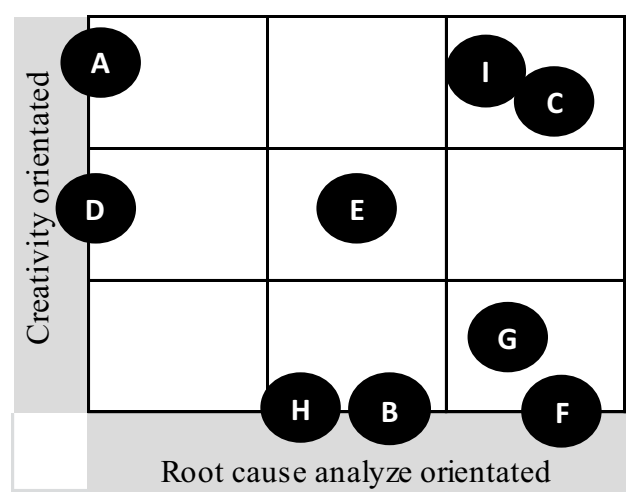

Fig. 2. Scatter diagram: PST creativity vs root cause analyze orientation

\section{CONCLUSIONS}

In conclusion, the concept of problem solving can be assessed from different angles as a set of tools or their applications combined with the organizational know-how culture. In fact, it is all about efficiency, not through complex solutions but through waste elimination and through the selection of the most efficient way to solve organizational problems. Further on, for a better foundation of the method, a discussion about and analysis of the appropriate criteria and scores should be addressed.

\section{References}

1. ***http://www.etymonline.com/index.php?term=problem, Accesed 5.01.2017

2. $* * *$ http://www.dictionary.com/browse/problem? $\mathrm{s}=\mathrm{t}$, Accesed 5.01.2017

3. ***http://www.businessdictionary.com/definition/problem.html, Accesed 5.01.2017

4. J. Liker, D. Meier, The Toyota way fieldbook: A practical guide for implementing Toyota's 4Ps (New York: McGraw-Hill, 2006)

5. P. Puvanasvaran, H. Megat., T. S Hong, and M. M Razali, Journal of industrial engineering and management, 2(1), 128-152 (2009)

6. A. F. Osborn, Applied Imagination, (Charles Scribner's Sons, New York, 1957)

7. R. Griffin and G. Moorhead, Organizational behavior (Nelson Education, 2011)

8. P. B Paulus, B. A Nijstad, Group creativity: Innovation through collaboration (New York: Oxford University Press, 2003)

9. D. L Nelson, J. C Quick, Organizational behavior: Science, the real world, and you (Mason, OH, USA: South-Western Cengage Learning, 2013) 
10. L. L Thompson, The social psychology of organizational behavior: Key readings (New York: Psychology Press, 2003)

11. L. K. Stroh, G. B Northcraft, M. A Neale, Organizational Behavior: A Management Challenge (Psychology Press, 2003)

12. C. Williams, Principles of management (Mason, OH: South-Western Cengage Learning, 2009)

13. N. Kock, Emerging E-collaboration concepts and applications (IGI Global, 2006)

14. R.L. Goodden, Lawsuit!: Reducing the Risk of Product Liability for Manufacturers, (John Wiley \& Sons, 2009)

15. T.Ohno, Toyota production system: beyond large-scale production, (Diamond. Inc., Tokyo, 1988)

16. C.V. Kifor, C. Oprean, Ingineria calităţii: îmbunătăţirea 6 sigma (Editura Universităţii " Lucian Blaga", 2006)

17. V. Pareto, The mind and society (Рипол Классик, 1935)

18. K. Lewin, Force field analysis, The 1973 Annual Handbook for Group Facilitators, 111-13 (1946) 